\title{
DA PÁGINA AO PALCO - A ARTE \\ MINIMALISTA DO CORPO EM MAX \\ Martins e Sankal JUKU ${ }^{1}$
}

FROM PAGE TO STAGE - THE MINIMALIST BODY ART

of BODY IN MAX MARTINS AND SANKAI JUKU

\author{
Gunter Karl Pressler* \\ * Universidade Federal do Pará \\ Belém do Pará, PA - Brasil \\ ORCID 0000-0002-1221-2946 \\ Sandra Mina Takakura ** \\ ** Universidade de São Paulo \\ São Paulo, SP - Brasil \\ ORCID 0000-0002-6882-0174
}

\section{Resumo}

O poeta Max Martins (1926-2009) estabeleceu em sua obra diálogos intensos com outras culturas, particularmente com a da Ásia. Já a assinatura dos seus poemas, que lembra um ideograma/logogram, aponta para uma síntese minimalista de toda obra como uma construção poética entre o Ocidente e o Oriente - este último compreendido como construção discursiva de inúmeras Ásias. Nosso artigo parte da obra de Max Martins, no contexto da poesia moderna, e da obra do grupo Sankai Juku (fundado 1975), no contexto da dança teatral Butoh, que teve o seu início na segunda metade do século XX, a fim de encontrar e ressaltar o ponto de convergência no movimento minimalista da linguagem artística dos corpos, na poesia e na dança-teatro. A interpretação comparativa visa significar a linguagem artística do espaço em branco e o preenchimento à tinta preta no papel, na poesia, e os corpos brancos em um fundo escuro de um palco construído e adaptado à materialidade/corporalidade no Butoh.

Palavras-chave: Max Martins; arte minimalista/corpo; Butoh; Sankai Juku.

\section{Abstract}

Max Martins's (1926-2009) poetic works engaged in frequent dialogues with other cultures, particularly with Asian cultures. From the start, the signature in his poems, which resembles

\section{Resumen}

El poeta Max Martins (1926-2009) estableció en su trabajo diálogos intensos con otras culturas, particularmente con la de Asia. La firma de sus poemas que recuerda un ideograma/logogram

1 Gunter Karl Pressler agradece ao CNPq que lhe destinou uma Bolsa de Produtividade (2013-2015). 
an ideogram/logogram, already pointed to a minimalist synthesis of all work as a poetic construction between East and West - the former understood as a discursive construction of countless Asias. This paper focuses on Max Martins's works, in the context of modern poetry, and the Sankai Juku troupe (founded in 1975) in the context of Butoh dance theatre, which arose in the second half of the $20^{\text {th }}$ century, in order to find and highlight the point of convergence between poetry and dance theater in the minimalist movement of artistic body language. This comparative interpretation seeks to illustrate the significance of the artistic language of a blank space, which in poetry is filled with black ink on paper, whilst in Butoh dancing, white bodies move against a dark background of a stage that was purposely built to adapt to their materiality/corporality.

Keywords: Max Martins; minimalist art/ body art; Butoh; Sankai Juku. apunta a una síntesis minimalista de toda obra como una construcción poética entre el occidente y el oriente, el último comprendido como construcción discursiva de innumerables Asias. Nuestro artículo parte de la obra de Max Martins, en el contexto de la poesía moderna, y de la obra del grupo Sankai Juku (fundado 1975), en el contexto de la danza teatral Butoh, que tuvo su inicio en la segunda mitad del siglo XX, a fin de encontrar y resaltar el punto de convergencia en el movimiento minimalista del lenguaje artístico de los cuerpos, en la poesía y en la danza-teatro. La interpretación comparativa pretende significar el lenguaje artístico del espacio en blanco y el relleno a la tinta negra en el papel, en la poesía y los cuerpos blancos en un fondo oscuro de un escenario construido y adaptado a la materialidad/corporalidad en el Butoh.

Palabras clave: Max Martins; arte minimalista/cuerpo; Butoh; Sankai Juku.

A capa dos Poemas Reunidos (1952-2001) (Figura 1) mostra a assinatura de Max Martins, um logograma/ideograma de algum país asiático, mas se trata de um pictograma do nome do poeta, que estabeleceu diálogos com outras culturas, particularmente com a Ásia.

Max Martins, poeta paraense que, apesar de nunca haver se estabelecido na Ásia, possuia um olhar que transcende o mero vislumbre ocidental acerca da cultura asiática e do corpo asiático. $\mathrm{O}$ poeta escreve por sonhar um mundo imaginado, explora, dá corpo ao desconhecido e coteja uma representação que extrapola o dito orientalismo da representação do território e do corpo "exóticos", sempre externos constituídos como saber epistemológico que se funda como o oposto binário à racionalidade cartesiana, e ao corpo masculino, heterossexual, branco, cristáo e ocidental ${ }^{2}$.

2 Cf. Edward W. Said (2003) que versa sobre o saber epistemológico acerca da construção de um oriente que legitima e justifica a superioridade do ocidente. Dominaçáo esta que se estente ao corpo que, de acordo com Michael Kimmel (1994), o corpo masculino, 


\section{MAX MARTINS}

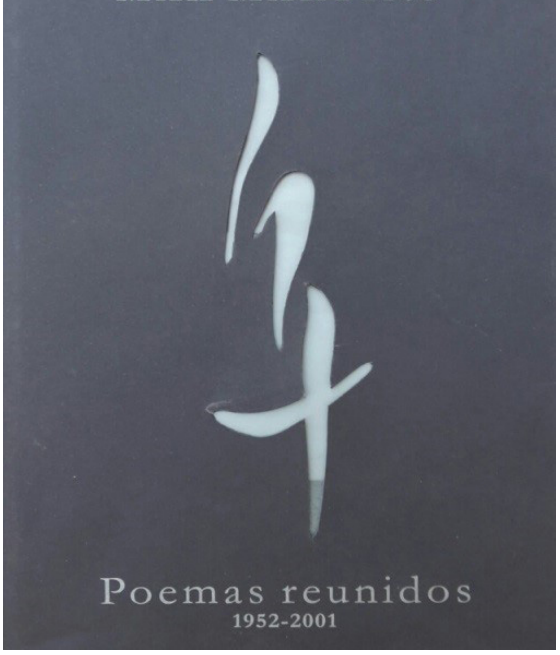

Figura 1: Capa da antologia Poemas Reunidos - 1952-2001 (MARTINS, 2001).

Max Martins adota este logo, de autoria de Vasco Cavalcante, que parece apontar para uma síntese minimalista de toda obra do poeta no que concerne esse olhar-se no desconhecido, traduzido em sua própria fala: "Eu sou o que não diz, sou o que não sei”. Muitas vezes foi apontado, em seus poemas e em seus depoimentos, um diálogo com uma construção discursiva de inúmeras Âsias cuidadosamente construídas, dentre as quais foram selecionados: "A um poeta japonês", "A Shan-hui", "Haikai", "Um jardim zen” e "Meditaçôes para Bashô" (MARTINS, 2001, pp. 76, 122, 139, 153 e 166), que indicam essas conexôes. $\mathrm{O}$ autor se constrói e se corporifica em seus poemas não de uma forma barroca a estilo de Gregório de Matos, mas por meio de uma arte minimalista sobre o papel. De forma similar, o Butoh - dança com fortes aspectos da teatralidade, que tem como figuras centrais Tatsumi Hijikata e Kazuo Ohno, e floresceu durante o pós-guerra no processo que ficou conhecido como ocidentalização

ocidental, branco, cristão, heterossexual hegemônico adotado como padrão genérico na sociedade ocidental subjuga o corpo do oriental, considerado "exótico", pagão, selvagem, incapaz de se ajustar ao padrão de masculinidade imposto, transita ora como possuidor de uma sexualidade promíscua, ora sempre em falta, por meio de uma assexualidade igualmente imposta. 
do Japão - se constitui como uma arte expressiva minimalista. Em sua segunda geração encontra projeção no Ocidente por meio do grupo Sankai Juku, que visitou o Brasil em várias ocasióes (2000, 2007, 2010, 2013 e 2016).

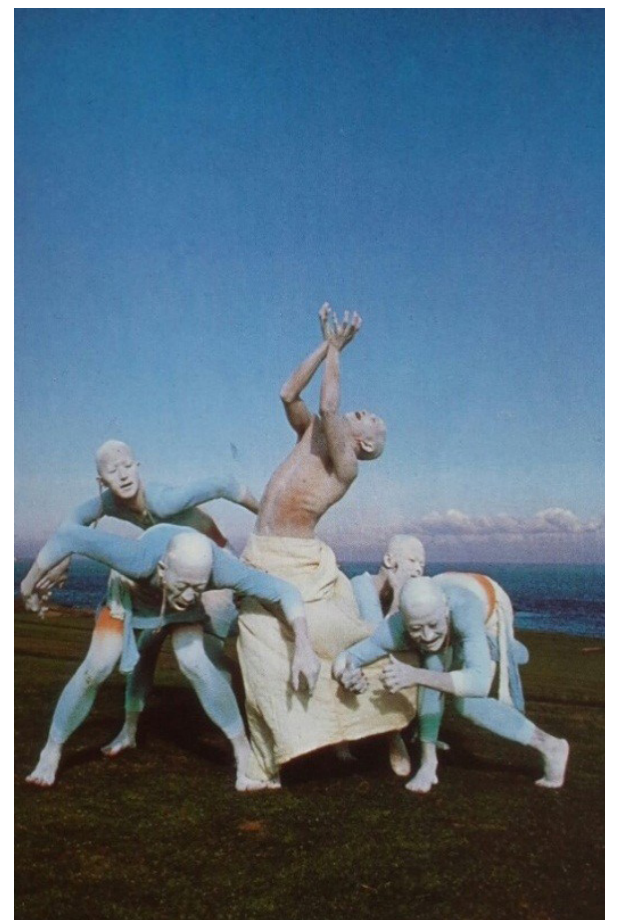

Figura 2: Fotografia de Alexandra Paszkowska (1983).

Este estudo preliminar propóe um diálogo entre os poemas mencionados de Max Martins e o Butoh em geral, e em particular com o espetáculo mais recente do grupo Sankai Juku, Meguri: Exuberância marinha, terra tranquila (2015). O ponto de convergência, nesse estudo, encontra-se no movimento mínimo da linguagem artística do corpo em uma seleçáo de poemas de Max Martins e no espetáculo Meguri de Sankai Juku. O primeiro explora a espacialidade no papel em que se tencionam os espaços em branco e os preenchimentos à tinta preta e, em particular, a materialidade do significante; e o segundo explora a potencialidade do cenário onde os corpos brancos dos artistas se inserem de forma a contrapor com a espacialidade do 
palco ou das instalaçóes, interagindo através de uma lingugem corporal espacilizada (Figura 2). Ambas consideradas minimal art, com elementos reduzidos, alcançam o ápice, aquilo que se chama "essência" ou "absoluto" da expressão poética, transgredindo os limites do homem/da mulher, e a materialidade do orgânico/do inorgânico.

Esse estudo escrutina as experiências do Butoh do grupo Sankai Juku e a criação poética de Max Martins, contrastando a construção espacial e os movimentos corporais com a construção poética, a fim de chegar a uma interpretação da relação artística e poética com o mundo. $\mathrm{O}$ mundo que reencontramos pela percepção e reflexão do próprio corpo na escrita e na dança frisa aquilo que Maurice Merleau-Ponty constata na sua Fenomenologia da Percepção: "[L]onge de meu corpo ser para mim apenas um fragmento do espaço, para mim não haveria espaço se eu não tivesse corpo" (1999 [1945], p. 148), i.e., o corpo e a escrita se configuram como uma textura no espaço e - no final - são espaços.

Contrastar a poesia de Max Martins e a arte do grupo Sankai Juku, neste sentido, partiu da percepção estética da nossa consciência que "não é apenas um registro passivo do mundo, mas constitui ativamente esse mundo, ou 'pretende' fazê-lo" (EAGLETON, 1997 [1983], p. 76). A atividade criativa corresponde àquela "essência" na obra de arte, chamada eidos (o termo ideia deriva da palavra eidos, em grego, imagem), provoca num momento da percepção estética (forma, cores, i.e., o corpo da arte) um impacto do abstrato da reflexão com a materialidade do concreto. A operação interpretativa constitui a hermenêutica entre o leitor, a obra e o autor. A obra de arte estimula a percepçáo e a consciência do leitor e apreciador da arte, que se posiciona e se articula diante dela. A chamada "redução fenomenológica" valoriza, particularmente no pensamento de Walter Benjamin, o objeto concreto e pequeno ("die kleinen Dinge", 2002 e 2006) - não só o objeto de massa (a batalha) como também o de arte (a obra canônica) -, a fim de não só "voltar às coisas", mas ir às estruturas e processos da própria consciência na percepção do mundo pela arte, neste sentido pensando mais na ligação entre "cristalografia e poesia" de Novalis $^{3}$ do que na epistomologia moderna. Benjamin

3 Cf. Ulrich Stadler 2011, p. 74-76; ele ressalta a atenção de Novalis para as coisas pequenas, a partir de uma resenha sobre uma obra menos conhecida de Leonardo da Vinci. Irene 
entende muito bem, como leitor e estudioso de Immanuel Kant, o que significa tornar possível o conhecimento pelo processo mental no contexto fenomenológico da reflexão sobre o "visível e invisível", ou nas palavras de Merleau-Ponty "Retornar às coisas mesmas é retornar a este mundo antes do conhecimento do qual o conhecimento sempre fala, e em relação ao qual toda determinação científica é abstrata, representativa e dependente" ". A inclinação ao mundo concreto, ao material, ao corpo - “Leib”, em alemão, diferente de “Körper” (ボデ $\nmid$, bodi) $)^{5}$ - segura o Benjamin para não cair no mundo idealizado de abstraçóes pela própria dinâmica de sistemas epistemológicos.

No interior da antologia Poemas Reunidos encontramos o poema completo do ideograma. A inversão do branco/preto e do visível/invisível se completa na sobrecapa, que mantém o ideograma cortado como se fosse uma porta aberta, favorecida pela editoração consciente que transforma a capa e a sobrecapa em parte do todo “objeto" estético (Figura 3).

No instante da aproximação ao fenômeno percebido e à conscientização expressa em língua, reformulamos a proposição de Terry Eagleton - "a linguagem poética materializava a própria essência da realidade" (1997, p. 77) - de seguinte forma: a materialidade da realidade (corpo) se transforma na materialidade da linguagem poética, a escrita-fala (as propriedades fônicas e gráficas, e portanto a escrita oralizada). A "transformação/tradução" só pode ocorrer na linguagem poética e não na linguagem comum, pois a primeira não comunica, ela "descomunica" - falando nas palavras de Haroldo

Bark chama atenção para o círculo de motivos de Novalis que, além do mito, das lendas e da medicina e biologia, se intensificaram os motivos da mineralogia para configurar os símbolos de existência do poeta, por exemplo, logo no início d'Os Discípulos em Sais. Novalis se formou entre 1795 e 1797 , numa região de exploração de minas. A cristalografia foi seu estudo predileto para pensar "formas de auto-organização material" (BARK, 2011, p. 94 e p. 106-110). Ele estudou detalhadamente a obra do seu professor Abraham Gottlieb Werner, Von den äusserlichen Kennzeichen der Fossilien [Das marcas externas das fósseis] (1774); cf. no final o novo espetáculo do grupo Sankai Juku.

4 Merleau-Ponty, 1999, p. 4. Traduzimos a palavra "significativa" (signitive, no original) como representativa por razóes interpretativas no contexto da arte.

5 ボディ trata-se de um empréstimo do inglês, e sua escrita é mereamente fonética. Em japonês, há vários termos para o corpo: karada 体, shintai 身体, o corpo que pratica esportes, $m i$ 身 o corpo físico, corpo do "eu”, e durante a segunda guerra o kokutai 国体. Acho bom tirar o ボディ, o corpo nacional (ver GREINER, 1988). 
de Campos ${ }^{6}$ - as coisas da realidade (“Lebenswelt") 7 . A linguagem poética torna a materialidade consciente e esteticamente vivenciável ou, melhor ainda, experienciável ("erfahrbar"): na própria leitura e recitação de poemas e na imitação da dança Butoh pelo olhar e ouvir.

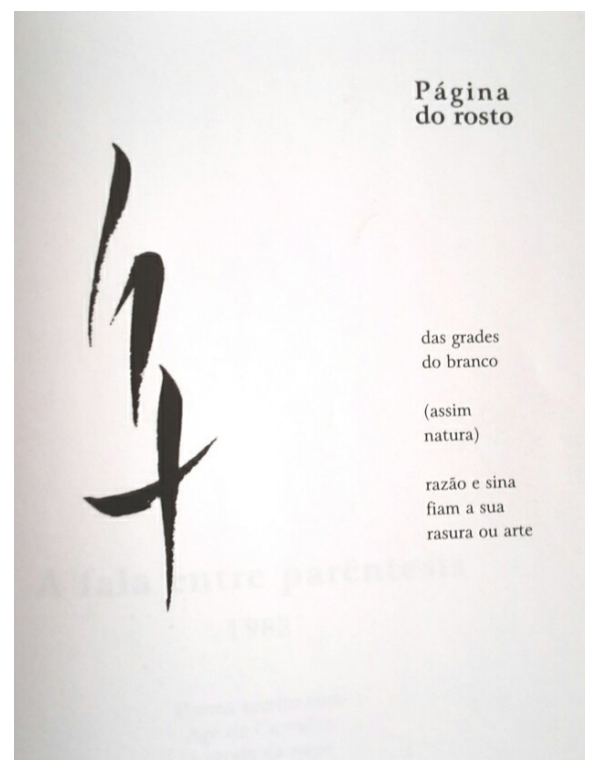

Figura 3: Poema (MARTINS, 2001, p. 181).

A contemplação perpassa pelo mínimo do movimento e pela "redução" ao impacto do sentir estético do abstrato ao concreto. A nossa interpretação não investiga como o poeta e o grupo de dança sentiram ou intencionaram criar palavras e movimentos, espaço e

6 Em 1967, Haroldo de Campos publica seu primeiro e importante artigo nesta linha de pensar a tarefa de traduzir. "A Palavra Vermelha de Hölderlin", em que a caracteriza como "verdadeira metafísica do traduzir" (1972, p. 95). A fidelidade ao texto literário existia para Hölderlin na "forma". "Na tradução de um poema, o essencial não é a reconstituição da mensagem, mas a reconstituição do sistema de signos em que está incorporada esta mensagem, da informação estética, não da informação meramente semântica", salienta o poeta e tradutor. Num artigo escrito três anos depois, Campos identifica esse ponto com o conceito de "descomunicação" ("O Texto como Descomunicação", 1976); cf. Pressler (2018) em relação às traduções dos poemas de Max Martins.

7 No contexto da fenomenologia, aparece o termo "Lebenswelt" (o mundo da vida/mundo vivido), para frisar a inclusão da subjetividade e o mundo orgânico diante da "objetividade" do pensamento do século XIX, marcado pelas ciências exatas e o avanço das tecnologias. 
tempo, mas como as linguagens em tempo e espaço se expressam e se relacionam na obra de arte. A nossa preocupação teórica e metodológica visa mostrar como o imanente ("essência") na obra de arte corresponde/comunica com o imanente do leitor e do apreciador da arte (cf. mais adiante, os exemplos em torno das novas aplicaçóes midiáticas da obra de Vicent van Gogh). Essa "imanência” da (des) comunicação estética permite comparaçōes de obras de arte de áreas e tempos diferentes. Desta forma, a linguagem não é "expressão" (tornar o interior para fora) de significados ou de sentidos; ela é representação da materialidade do mundo que se torna consciente. Se a linguagem não fosse medium ou "signo" que transporta "significados", como compreendê-la? Apreendê-la como um instrumento impregnado pela relação mecânica entre significante e significado? Não será possível.

Se entendemos o significado não como fixo ou incorporado no significante mas como móvel, isso permite abrir mão do pensamento dual/bipolar ao estabelecer sentido em um fluxo contínuo el ou ininterrupto. A significância não é um significado revestido de palavras. A linguagem poética é uma "linguagem solitária" (EAGLETON, 1997, p. 84), tanto na busca quanto na criaçáo concreta da obra. Podemos entender isso no "ou" final do poema, e em outros poemas, por exemplo no poema “Um Jardim Zen” (2001, p. 153), na metafórica da "pedra" que recorre às obras dos poetas nos metadiscursos acerca da criação poética.

\section{A UM POETA JAPONÊS}

O mundo

é sonho é real
não sei
o que é sonho o que é real
ouna sou

(MARTINS, 2001, p. 166)

Posto isso, o poeta/o artista (veja o espetáculo Meguri) busca, na sua solidão, o inorgânico para se comunicar ou expressar. A linguagem em geral se diferencia da linguagem do homem, como 
postula Benjamin, a fim de comparar a melancolia do homem com a "linguagem das coisas". Trata-se de "línguas inomadas, não acústicas, de línguas próprias do material” (2011, p. 71), pois não só a linguagem do homem é pronunciada e percebida por ele. A linguagem poética/artística cria no mundo dos homens a comunicação da linguagem englobante da (natureza orgânica e anorgânica). E, como ressalta Benjamin, a tarefa do tradutor, - em geral - do próprio artista, que serve aos propósitos da criação artística do Butoh, significa "[...] $[\mathrm{t}]$ raduzir a linguagem das coisas para a linguagem do homem não consiste apenas em traduzir o que é mudo para o que é sonoro, mas traduzir aquilo que não tem nome em nome" (BENJAMIN, 2011, p. 64).

Em vez de continuar com Martin Heidegger (EAGLETON, 1997 , p. 85-91), preferíamos observar a relação da linguagem com o fenômeno em Jaques Derrida. Enquanto o significado está inerente ligado ao significante, o(s) sentido(s) existe(m) e se configuram independentemente do significante, mas não tanto dos significados, dependendo das forças identificadoras, da experiência e do contexto sociocultural e filosófico da reflexão interpretativa. "Os que lidam [...] com a poesia”, salienta Leyla Perrone-Moisés (1995, p. 6), interpretando Derrida, "[...] aceitam mais facilmente do que os filósofos a afirmação de que as obras verbais não têm um sentido único e final, mas uma significância, ou poder de criar sentidos que se renovam a cada leitura e através do tempo". Os significados não são invençóes individuais: são convenções estabelecidas no corpo da palavra e do signo desde os mitos e textos religiosos e sua linguagem simbólica. Pensamos a linguagem escrita, potencialmente poética, não no entendimento de uma "recriação da oralidade", mas no sentido do termo de Markus Schäffauer, a script Oralidade, que não esconde sua ligação com Jaques Derrida e com o criador do termo, Willi Erzberger (SCHÄFFAUER, 1998, p. 11-19). O termo designa "uma expressão histórica específica do logocentrismo ocidental que surge de uma combinação de fixação da origem logocêntrica e de uma teleologia grafocêntrico" (SCHÄFFAUER, 1998, p. 12), mas sim na sua particularidade como sublimação da poesia falada e cantada ao mundo duradouro da poesia escrita. 


\section{CORPUS e...}

O corpo se insere na teoria de Derrida pela da experiência vivida que deixa rastos impressos no corpo da vida e da morte, dentro e fora, tempo e espaço, etc. Tal fato aponta para o corpo enquanto espaço de possibilidade e impossibilidade simultâneas, onde os binários podem ser quebrados evidenciando a relação dos signos, dos significantes e dos significados enquanto uma cadeia que se contrasta por meio de traços e da diferença. Dessa forma, Derrida propóe a oposiçáo ao logocentrismo que, de acordo com Gayatri Chakravorty Spivak, aparece relacionada ao fonocentrismo.

Ele [Derrida] relaciona esse fonocentrismo ao logocentrismo - a crença que o primeiro e o útimo são o Logos, o Mundo, a Mente Divina, a compreensáo infinita de Deus, uma subjetividade criativa infinitamente, e, próximo ao nosso tempo, a auto-presença da auto consciência plena. (SPIVAK, 1997, p. lxviii) ${ }^{8}$

Derrida aponta o logocentrismo como etnocêntrico imbricado na "história do ocidente" ${ }^{9}$ em seus pensamentos binários e hierarquizados, como sensível e o inteligível, o dentro e o fora, o homem e a mulher, a vida e a morte etc.; e aponta que a China e o Japão através dos ideogramas podem ser vistos como locais onde as civilizaçóes se desenvolveram fora do logocentrismo, onde a escrita não reduz as vozes, mas as incorpora. Nesse sentido, o logo de Max Martins, que guarda a iconicidade relacionada à letra do alfabeto, congrega em si inúmeras ideias mantendo a possiblidade e a impossibilidade, a escrita e a fala, o preeenchimento e o espaço em branco.

8 No original: "He relates this phonocentrism to logocentrism - the belief that the first and last things are the Logos, the Word, the Divine Mind, the infinite understanding of God, an infinitely creative subjectivity, and, closer to our time, the self-presence of full self consciousness".

9 "Le logocentrisme est une métaphysique ethnocentrique, em un sens original et non 'relativiste'. Il est lié à l'histoire de l'Occident. Le modèle chinois ne l'interrompt qu'en apparence lorsque Leibniz s'y réfere pour enseigner la Caractéristique" (DERRIDA, 1967, p. $117 ; 1973$, p. 98$)$. 


\section{... MA enquanto possibilidade}

Michiko Okano (2013-2014, p. 150) aponta o ma enquanto "entre-espaço", "intervalo", uma possibilidade espaço-temporal que recorre enquanto lógica japonesa na cultura, como na arquitetura das casas - um espaço onde se coloca uma pintura, o kakejuku, na parede, um arranjo de flores, podendo ser um espaço para se receber visitas e construir arranjos de flores e realizar a cerimônia do chá (Figura 4). No teatro Noh, podemos apontar o espaço onde o artista se posiciona para atravessar uma passagem em direção ao palco. A origem do ma também pode estar relacionada ao "vazio" potencial "que tudo pode conter, e, portanto, da possibilidade de geração do novo" presente no I Ching (OKANO, 2013-2014, p. 151). Para Okano, uma vez que o espaço é preenchido, o ma deixa de existir, pois realiza a sua potencialidade.

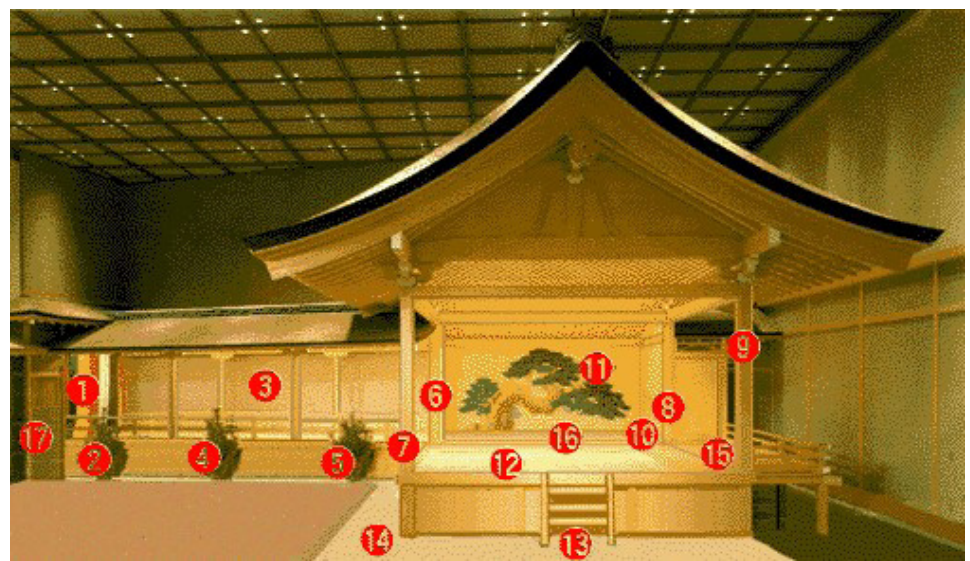

Figura 4: O ma enquanto "entre-espaço"; na imagem, o espaço entre os números 1 a 6 , Okano (2013-2014).

O ma existe enquanto uma ausência que denota uma presença, um devir, um suplemento, um traço; retomando Derrida, o corpo pode passar a ser o local onde se experimenta a linguagem artística, a articulação da diferença através dos traços que ligam significantes e significados, como no caso do Butoh, que veremos no próximo tópico, ou na preparação articulada do poema de Max Martins dedicado ao 
mestre do Zen, cujo nome é formado pela combinação dos ideogramas "bom" e "brilho":

\author{
A SHAN-HUI \\ Isto não é um poema \\ ainda \\ é só trabalho duro, muro \\ de pedra e nada - a pá \\ nas minhas mãos vazias \\ (MARTINS, 2001, p. 122).
}

O poema estabelece um diálogo com a fotografia (Figura 5) que promova a permanência de um momento de preparação dos corpos dos membros do grupo Sankai Juku, que cobrem seus corpos nus com uma maquiagem branca, entrando na representaçáo do corpo, no devir de desaparecer, apagando-o para ir além dele, de acordo com Kurihara (2000), que parte da asserção de Hijikata acerca do corpo e do corpo que dança o Butoh: "Como o corpo em si perece, possui uma forma. Butoh possui outra dimensão" ${ }^{10}$. O momento retratado é anterior à entrada no cenário, precisamente no plano do $m a$, pois o cenário torna-se o local potencial vazio de corpos a ser preenchido.

Okano (2013-2014, p. 153) aponta a recorrência do ma nas artes plásticas, enquanto "Yohaku" indica a página em branco no papel, ou seja, a área não preenchida no desenho, na pintura, uma pausa após a batida do tambor que ressoa um "eco"; no entanto, a alerta para o fato de que para ser ma o desenho ou a pintura devem se sustentar exatamente pelas áreas não preenchidas, o a partitura se sustenta pela pausa: "É a parte que nada contém, todavia, que tudo significa". Tal espacialidade se faz presente na arte minimalista do poeta Max Martins e do grupo Sankai Juku, naturalmente no jazz de John Cage e Morton Feldman ${ }^{11}$, na música clássica e na ópera moderna - por exemplo obras mais recentes e apreciadas de Beat

10 No original: "Since the body itself perishes,it has a form. Botoh has another dimension" (HIJIKATA apud KURIHARA, 2000, p. 25).

11 O compositor Edu Haubensack intitula seu artigo sobre Morton Feldman (1926-1987), Musik ohne Gewicht [Música sem peso], e ressalta Feldman como "mestre da lentidão, do silêncio e da repeitição variada" e sua relação com o tempo, em que a dimensão da percep- 
Furrer (2015) e de Toshio Hosokawa (2016), em que os dois títulos La Nottebianca [A noite branca] e Stilles Meer [Mar Silencioso] significam mais do que um comentário pode revelar. Mesmo que as óperas narrem uma história, elas são encenadas - como a música de Feldman -, como um "épico sem enredo" ("plotlessepic"), realizada por E.P. [Ezra Pound], onde, da catalisação de elementos em torno de focos de interesse ou vórtices, emerge, afinal, o imenso ideograma" (CAMPOS, 1977, p. 58). No teatro Noh, ocorre um processo similar ao haikai, "[ ...] a peça inteira... é reunida em torno de uma imagem... Nada tenho contra um longo poema vorticista" ${ }^{12}$. O Butoh está nesta tradição, como veremos mais adiante na leitura do peça Meguri, do grupo Sankai Juku.

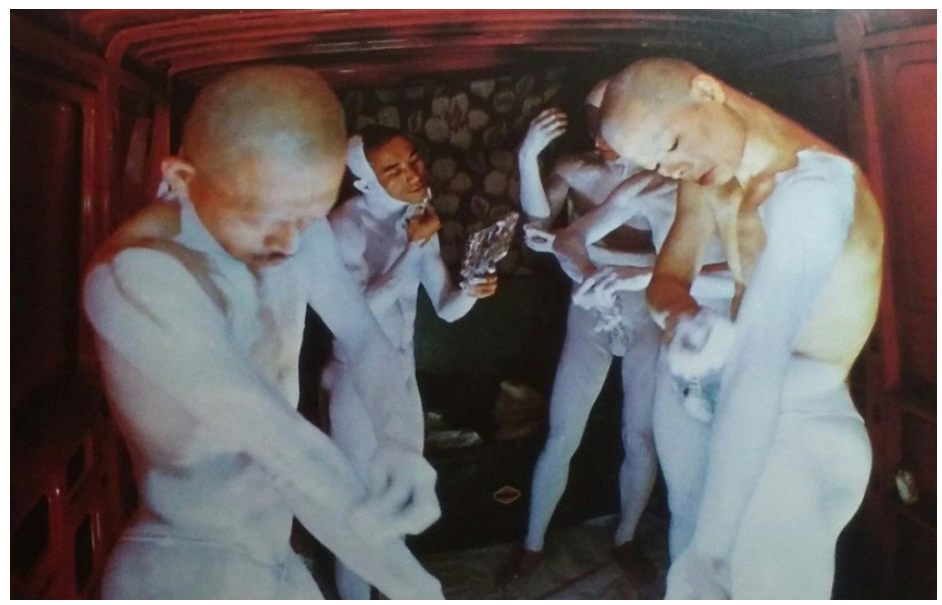

Figura 5: Os membros do grupo Sankai Juku pintando os corpos.

O espaço preparativo é o combi para o deslocamento da série de fotografias. Fotografia de Alexandra Paszkowska (1983).

A origem do haikai é apontada por Shuichi Kato e aprofundada no estudo ímpar de Shuichi Kato: "A caraterística formal do

ção transmite permanentemente entre o presente e passado. Cf. John Cage, 4’33”, disponível em: <https://www.youtube.com/watch?v=JTEFKFiXSx4>, acesso em 29/07/2017.

12 Ezra Pound apud Campos, 1977, p. 57. Sem poder abordar, nesta altura, visamos o complexo de reflexão e seu aprofundamento sobre $O A B C$ da Literatura, de E. Pound ( $11^{\text {a }} \mathrm{ed}$., 2006 [1934]) e a organização da antologia Ideograma (3a ed., 1994 [1977]). Também, nosso objetivo não analisa as obras sobre o ponto de vista "semiogenética" ou "ideogrâmico", como destaca Haroldo de Campos no seu prefácio à $3^{a}$ ed. "Fenellosa Revisitado". 
poema lírico da língua japonesa é que se trata de uma forma poética extremamente curta que vem sendo usada por séculos. Primeiro, o tanka [...] e, muito mais tarde, o haiku (poema de dezessete sílabas" (KATO, 2012, p. 84). O haikai, sendo minimalista, deixa os espaços vazios na página, constituindo uma arquitetônica espacial que com frequência é preenchido por desenhos a pincel por meio da técnica de carvão.

\section{Haikai e a espacialidade}

A fotografia de Alexandra Paszkowska (Figura 6) retrata dois membros do grupo Sankai Juku aparentemente brincando nas highlands próximo de Edimgburgo, na Escócia, em um flagrante momento de desconcentração humorística; porém, a inserção desta fotografia no livro ressalta este momento próprio do fazer arte. Tendo a imagem flagrada (como se joga os cabelos para trás) como ponto de partida, associamos um outro momento do fazer poético - o pensamento leve de desconcentração e lembrança entre Max e (A)n(ge)l:

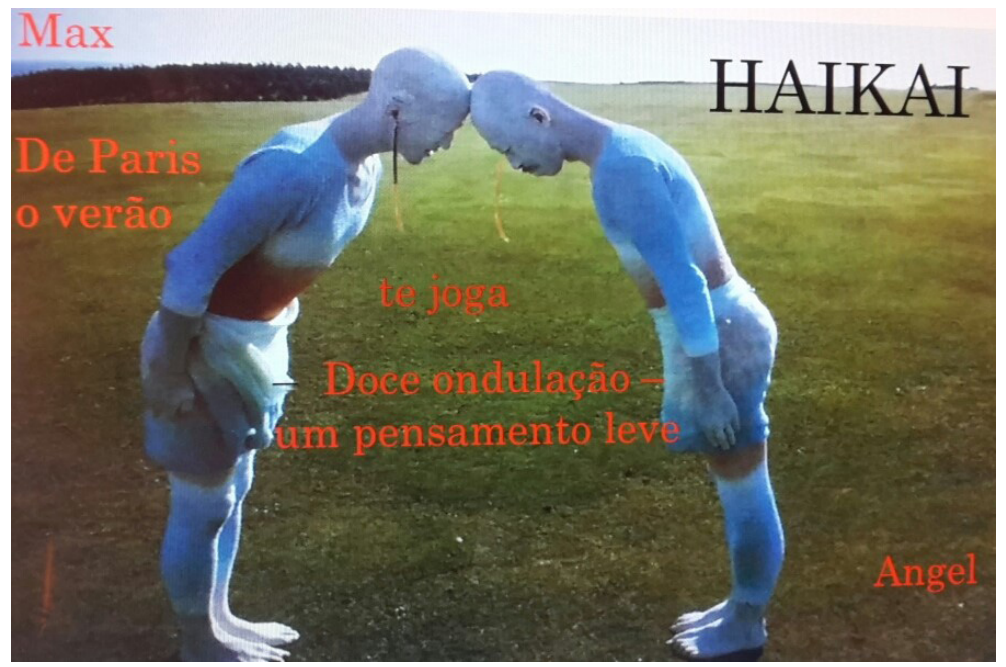

Figura 6: Collage Max Martins e Alexandra Paszkowska (1983). 
O poema, publicado em 2001, no livro Colmando a Lacuna, parte da antologia Poemas Reunidos, pode ser fruto de uma "doce ondulação"; um "pensamento leve" de Paris ${ }^{13}$ - pode ser na chegada à Gare d'Leste -, posterior a uma materialidade densa e corporal, como sugere o poema, de outros encontros, mais em Vienna, mais no leste, despedida na estação (oeste) de trem (Westbahnhof) em direção à capital francesa:

\section{WIEN, WESTBAHNHOF}

Real perfeito, o ato

A cerimônia de um poema

.......teve-me

Desvelar as significaçóes inseridas nas referências do espaço (Paris, Vienna) e do tempo (verão), a leveza do anjo (Angel) é a leveza do haikai; o ato oficial da "cerimônia" combinado com o "real perfeito" indica o hokku ou haiku. O poeta inverteu a ordem: o kiregi está no final, no meio kigo, a estação, e no início o lugar (NUNES, 2016, p. 42). No caso de Max e Angel, trata-se do passado ("De Paris"), mas o passado só é o outro lado do presente, que é o futuro. As implicaçôes do haikai e do renga "[...] 'no agora=aqui', no qual o passado é enterrado, e o amanhã é confiado ao novo dia” (KATO, 2012, p. 94), refletem-se na temática. "São poucos os versos de amor no haiku" (KATO, 2012, p. 87), por causa da brevidade (poema de 17 sílabas ), que não permite expressar uma emoção de longa duração.

Bashô distingue o haiku do tanka (e o renga com uma das suas formas), considerando o primeiro como expressão da experiência instantânea. Essa experiência não é emocional e nem sensitiva, é um tipo de sintonia entre o alvo da percepção (mundo exterior [Paris, pode ser no Gare d'Leste, ou Wien]) e o íntimo [Doce ondulação,

13 Francisco Queiroz observa o poema no dito e nas associaçóes possíveis, na linha do pensar trans(oci)dental, que o haikai "comunica [aquilo que] é essencial". Mas "para que o poema seja concretizado importa acima de tudo a capacidade de saber ver o que a natureza diz e é [Paris ou Escócia?]. A ondulação de uma brisa veranil desperta um novo estado de consciência, o qual é leve e tépido como um verão parisiense" (2016, p. 9) Natureza? Veja a indicação "verão", em vez de um termo sazonal de verão, p.e., "flor espinhosa" (KATO, 2012, p. 102). Poema de Buson? É uma experiência urbana europeia? "A percepção dispensaria a explicação". Não tanto! 
teve-me]; surge num instante [Max] e se extingue noutro [Angel] (KATO, 2012, p. 102).

Mas, no ato da leitura, nota-se uma transgressão à forma, e o poema ganha sentido emocional e futuro: "O 'encontro' com a pessoa amada é um fato futuro [ou passado], e o 'sentir a coisa' está no presente" (KATO, 2012, p. 89).

A morfologia estuda a configuração externa da matéria-palavra e/ou de um órgão ou ser vivo, enquanto que o fonema recua para o interior onde a palavra nasceu - no corpo. A interpretação do sentido ou se contenta com a superfície do espaço poema (escrita e significados), ou se arrisca na corporalidade do espaço do médium da linguagem verbal (fala e som): "o ato... teve-me". Podemos dizer que, com um outro poema, dedicado a Edison Ferreira, Max Martins alcança as características do ideograma, centralizado no "eu/ego" como o averso da relação amorosa:

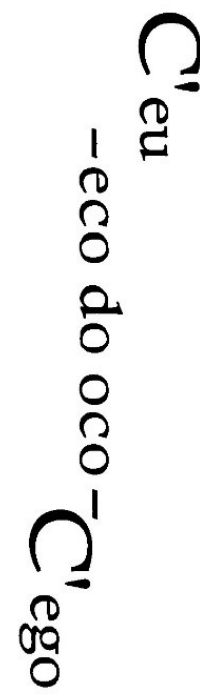

Figura 7: Max Martins (2001, p. 172). ${ }^{14}$

14 Colocamos o poema na vertical respeitando a forma japonesa de escrita. 
O corpo se insere, segundo Derrida, pela experiência vivida, e deixa rastros impressos no outro corpo, o da linguagem poética. O elemento visual na poesia de Max Martins, diferente da poesia japonesa "que lhe é intrínseco, que participa de sua própria natureza" (CAMPOS, 1977, p. 63) - digamos "materialidade”, está no branco (o branco significativo, não é só um espaço entre versos). A distância entre o título Wien, Westbahnhof e o tu do poema é "real", a distância entre Paris e Viena: 1.236 quilômetros. A escrita ocidental, salienta Haroldo de Campos, só poderia "imitar" a visualidade do ideograma chinês ou japonês, que Ernest Fenollosa identifica como um "processo de compor, duas coisas conjugadas [que] não produzem uma terceira, mas sugerem alguma relação fundamental entre ambas" (CAMPOS, 1977 , p. 64). As duas "coisas" ligadas não produzem um terceiro em uma síntese dialética, da oposição de contrários uma vez que, ordenadas em uma relação de diferença por traços derridareanos, criam uma relação homoerótica em termos de Octávio Paz (1994), que parte do Banquete de Platáo, ao [re]produzir, por meio do intelecto, da relação entre mestre e aprendiz. Um homem maduro seduz intelectualmente um jovem, resultando na experiência retratada em um poema, revivi$\mathrm{da} / \mathrm{rememorada} / \mathrm{ressignificada} \mathrm{a} \mathrm{cada} \mathrm{leitura.} \mathrm{Pode} \mathrm{ser} \mathrm{que} \mathrm{a} \mathrm{aplicação}$ do renga, da escrita em quatro máos (lembramos do livro $A$ Fala entre Parêntese, 1982), seja uma tentativa de alcançar a potencialidade do ideograma e se contentar com "duas coisas conjugadas" sem um resultado (fora da publicação do ato criativo).

\section{Corpo no Butoh...}

O Butoh representou uma forma de resistência contra a ocidentalização do Japão, ao mesmo tempo que se buscava uma arte que congregasse os valores e a visão de mundo que se transformava em estética e em discurso corporal. O Butoh se realiza no espaço conhecido como $m a$, de acorco com Christine Greiner (1998), onde a representação do corpo morto, do ser trancende os binários, morte e vida, homem e mulher, macho e fêmea, masculino e feminino dança por meio de movimentos convulsivos, de girar os glóbulos oculares para se olhar para dentro, rompendo o dentro e o fora, tornam-se insetos, pedras, flores. 
A visão do impacto dialético entre o chamado ocidente $\mathrm{e}$ oriente é apresentada por Byung-Chul Han, um coreano de Seoul, que se fixou há trinta anos na Alemanha para estudar filosofia, nas reflexôes sobre a transição da Modernidade à Pós-Modernidade:

A sociedade do século XXI [é] uma sociedade de desempenho [...] seus habitantes não se chamam mais 'sujeitos de obediência', mas sujeitos de desempenho e produção [...] O plural coletivo da afirmação Yes, we can expressa precisamente o caráter de positividade da sociedade de desempenho (HAN, 2015, p. 23, 24).

Com muita perspicácia, Han observa que a "sociedade disciplinar de Foucault, feita de hospitais, asilos, presídios, quartéis e fábricas, não é mais a sociedade de hoje. Em seu lugar, há muito tempo, entrou uma outra sociedade, a saber, uma sociedade de academias de fitness, prédios de escritórios, bancos, aeroportos, shopping centers e laboratórios de genética" (HAN, 2015 [2012], p. 23, 24).

Quais são as reaçóes da lírica e da dança e suas relaçóes ao devido corpo na Pós-Modernidade, ou melhor, na transição da Modernidade de século 20 à Pós-Modernidade do século 21? Ela está na contemplação da "substância" enquanto redução de linguagens e movimentos mínimos? A Minimal Art seria aparentemente um "pano cinza”, pergunta Han, apoiando-se na metafórica de Walter Benjamin, "[...] forrada por dentro com a mais incandescente e o mais colorido revestimento de seda que já existiu" (2015, p. 34)? A resposta encontra-se, segundo Han, na "força imunológica" do ser humano: "Os desempenhos culturais da humanidade [...] devem-se a uma atenção profunda, contemplativa. A cultura pressupóe um ambiente onde seja possível uma atenção profunda, cada vez mais deslocada por uma forma de atenção distinta, a hiperatenção (hyperattention)" (HAN, 2015, p. 33).

Assistir a um espectáculo de Butoh e ler/escutar um poema de Max Martins significa contemplar uma paisagem, como Paul Cézanne diz, até ela "pensa-se em mim" (2015, p. 37) ou como Akira Kurosawa no filme Sonhos (1990), no qual num episódio o visitante da exposição de quadros de Vicent van Gogh entra no quadro Campos 
de Trigo com Corvos (1890) ${ }^{15}$. Neste e em muitos outros sentidos, "a arte é uma 'ação expressiva'” (HAN, 2015, p. 37).

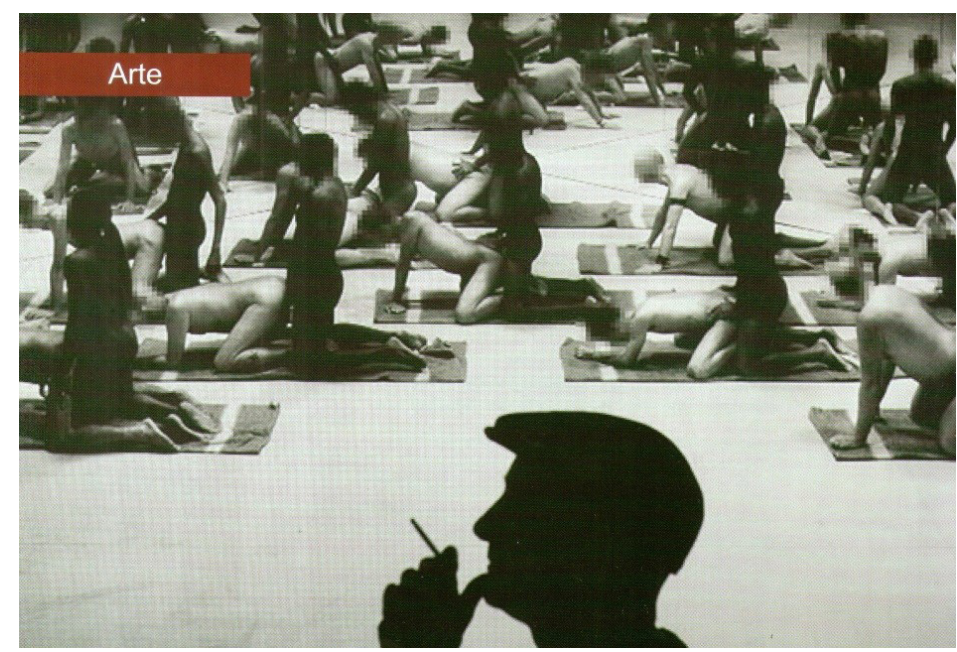

Figura 8: Collectanevs (Lima), 2009, p. 50.

Uma arte expressiva do corpo é apresentada pelo artista Santiago Sierra na sua vídeo instalação Los Penetrados (2008). Pode se perguntar, como o fez a revista Collectanevs (Lima), no 7, agosto/setembro de 2009 (Figura 8), “¿Puede la Pornografía ser arte Política?”. Ou pode e deve ser considerada uma instalação na Pós-Modernidade, que Byung-ChulHan desenha e acaba em depressão e fracassos em comparação ao apresentado e interpretado na arte lírica e na dança. Nesse vídeo, corpos reais penetram nos corpos reais. O significante é puro suporte visível de um dado significado político, na visão do artista. "Todo arte es político pero normalmente quien se fotografia com el poder assegura tenersólo um interés poético" (2009, p. 51), constata Sierra. Mas, com essa simplificação de politização barata e

15 Não por acaso, a obra de Van Gogh é matéria de instalaçôes multimídiaticas e games, p.e., na exposição atual FILE 2016. Festival Internacional de Linguagens Eletrônicas, em São Paulo, Mac Cauley apresenta The Night Café, "[...] um ambiente imersivo de realidade virtual que permite que você explore o mundo de Vicent van Gogh”. Disponível em: <http://www.sesisp.org.br/cultura/>, acesso 27/07/2016. Cf. também a exposiçáo Van Gogh Alive, disponível em: <http://www.monopol-magazin.de/Van-Gogh-Alive-Berlin-Multimedia-Show>, acesso 27/07/2016. 
aparentemente retórica, ele não "penetra" naquilo que seria o "artístico/o poético" numa representação do mundo ${ }^{16}$. A provocaçáo vale no campo da arte por meio do choque e do rompimento com o que já foi feito até então na história da arte, que demanda continuamente um processo mais radical e sobreposiçóes entre a arte e a realidade, a coisa que se confunde com o material que se fez uso, em detrimento da força criativa e da técnica, amarras tradicionalistas contrárias à mente criativa do artista. Bakhtin entende por "objeto estético na sua singularidade e estrutura puramente artística” (2010, p. 22), concebida de forma "teleológica", o "objeto estético arquitetônico", que não se pode confundir com o material do qual se fez uso, como o próprio corpo.

A obra de arte, enquanto produto acabado, está sujeita ao ciclo de produção, distribuição e de consumo no mercado da arte, que reifica desejos em bens adquiríveis, que em processo ininterrupto constrói e desconstrói novos objetos de desejo em um mundo pós-moderno, onde o objeto torna-se marcaçóes identitárias cada vez mais fragmentárias (HALL, 2004; ULLRICH, 2016). O mercado encarregou-se de manufaturar desejos, sempre perdidos na entrada do homem na cultura, sempre "[...] 'o desejo do Outro' - que se afirma ser intersubjetivo, mediado pelo outro: em contraste à pulsão (drive) 'autistica' contida no seu circuito", fadado a repetir a busca pelo objeto e a sempre se confrontar com a perda; jouissance, ou o gozo, a satisfação plena, por sua vez, fora sacrificada em parte quando este se tornou sujeito ${ }^{17}$. Ao nos tornarmos sujeitos do desejo, perdemos parte do gozo e assumimos que nossos desejos são na realidade desejo do Outro, e ansiamos em assumir a posição de voyeurs do mundo contemporâneo, contemplando através do olhar a arte os corpos e a corporificaçáo dos desejos dos Outros que recepcionamos enquanto nosso.

16 Muito diferente dos movimentos de performances militantes na década de 1960 de Otto Mühl, Valie Export e Peter Weibel; ações contra a opressão do corpo e da sexualidade na arte e na sociedade; cf. Anna Schober (2009).

17 Cf. "[...] a definition a 'desire of the Other' - that is to say intersubjective, mediated by the other: in contrast to the 'autistic' drive, contained in its circuit" (ZIZEK, 1992, p. 229). 


\section{Corpo e sujeito em Max Martins e Sankai Juku}

Uma das mais conhecidas fotografias do poeta Max Martins mostra-o andando na praia de Marahu - parece um monge budista caminhando na trilha de Lao-tsé, equilibrando o ser humano com o cosmo, e para isso não precisa de um guardião nem de uma fronteira.

O correr ou o cavalgar não é um modo de andar novo. É uma andar acelerado. A dança, por exemplo, ou balançar-se, representa um movimento totalmente distinto [...] Comparada com o andar linear, reto, a dança, com seus movimentos revoluteantes, é um luxo que foge totalmente do princípio do desempenho (HAN, 2015 [2010], p. 45).

Podemos dizer que a poesia de Max - diferente do seu andar linear na fotografia, que não pode ser pensado fora dos seus diários, montagens, colagens e desenhos - se movimenta em linhas curvas de um pincel de caligrafia; e os movimentos da dança Butoh - quando saem daquele espaço $m a$, em que a música parou ou ainda náo começou - se agitam em vários sentidos (melhor ver um espectáculo do grupo Sankai Juku de cima para perceber a divisão do espaço).

E, nas sugestóes e nos espaços sem preenchimentos tanto do papel em Max Martins, e quanto das pausas - "[...] é o intervalo entre dois sons, a distância temporal, é o comprimento da duração do silêncio" (KATO, 2012: 109), bem observável nos espetáculos de Sankai Juku - que precedem ou seguem os movimentos mínimos no palco congeladas em fotos sinalizam um devir, um espaço em potencial a ser preenchido pelo leitor através da sugestão. Encontramos os mesmos espaços apontados por Wolfgang Iser, "O lugar vazio como conexão potencial" (1999 [1976], p. 126) no processo de leitura em que o leitor preenche esses espaços para que haja compreensão para se entender como entre-espaço da cultura japonesa ma. $\mathrm{O}$ sujeito espera o momento exato de viver e se depara com a própria morte, problemática que se insere na relação entre o espaço, o processo de enunciação e o fechamento da narrativa. 


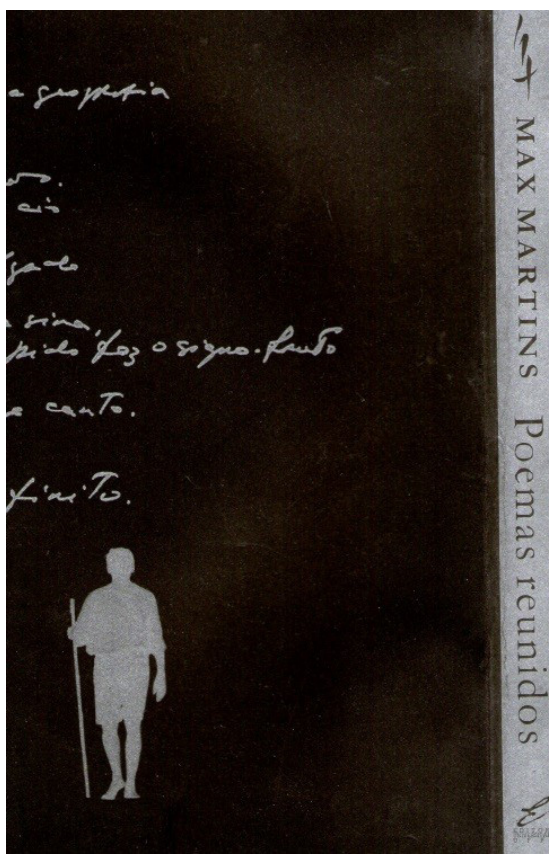

Figura 9: Contracapa da antologia Poemas Reunidos - 1952-2001 (MARTINS, 2001).

Aqui se retomam as palavras de Max Martins que abrem esse estudo: "Eu sou o que não diz, sou o que não sei". . Este ser estrangeiro em seu próprio corpo se coloniza e rompe com o dentro e o fora. Mas também o eu se diverte e se distrai levemente sem o remorso ontológico (no contexto dos poemas "Exílio 1" e "Exílio 2"), com um pouco de ironia romântica (entre-tenho).

\section{EU}

que me entretenho

interditado

(MARTINS, 2001, p. 147)

As viagens artísticas imaginativas de Max Martins rompem os territórios proibitivos, as paisagens não vistas e a expressividade não sentida. Aqui converge com o grupo Sankai Juku que se lança, primeiramente, em territórios estranhos, a exemplo do espetáculo Umusuna: Memória Antes da História, que estreou na Bienal de Lyon, 
na França em 2012, e se apresentou no Rio de Janeiro e em São Paulo em 2013. Por meio do desconhecimento, o outro é ontologicamente constituído como tal, um corpo estrangeiro em meio a vizinhos.

$\mathrm{Na}$ página oficial do grupo, é possível ler a descrição do conceito do espetáculo, mencionado em língua japonesa, a descrição da criação de um mundo anterior à história, quando se vivia e não se rememorava para contar.

\begin{abstract}
Abaixo do céu inflinito, uma nação finita se instala, a noite escura em seu fim transforma-se para a aurora por meio da inserção corajosa da luz, o céu e a terra, a existência e o nada, a pessoa e a pessoa, 'a memória antes da história', mesmo sendo diferentes, nasceu um ser indivisível que congregava dois em um, fez o seu ninho, a terra se torna sua mãe falecida, engrava sobre ela o tempo que se movimenta [...] Amagatsu Ushio afunda ao pisar o cháo, pega a areia, atravessa pela segunda vez por meio da dança solitária e parece proteger o tempo (SANKAI JUKU, 2016).
\end{abstract}

O espetáculo permite ao público constituir a sua própria narrativa, de coexistência dos contrários, de duas espaciadades no mesmo palco dividido ao meio coberto por areia. Há um momento crucial em que Amagatsu Ushio se posiciona no meio da divisão, torna-se o próprio corpo estrangeiro no meio dos vizinhos: o lugar vazio é preenchido, e o elo recuperado. As linguagens se conectam com a realidade novamente, ironicamente por uma representação não verbalizada, de um olhar que observa o público e assume por vezes do palco a posição de vouyeur, reduzido a Outros, ou ampliado para que posa ditar o desejo. E, nessa busca, há o momento de autorreflexão em que se faz uma pausa. Nota-se, nesse instante, que o que fica é o vazio, não é espaço, não é tempo, mas um vazio tremendo e assustador. Assustado porque talvez seja reconhecida a condição humana solitária, fadada a ter esse espaço vazio em potencial, preenchido somente por uns instantes, continuamente à espera de ser preenchido novamente, e habitado por fantasmas de memórias que insistem invadir esse espaço.

Nosso breve estudo propóe compartilhar as experiências poéticas da poesia e da dança-teatro Butoh. Foi realizada uma leitura 
experimental dos poemas selecionados de Max Martins e das peças do grupo Sankai Juku, particularmente o mais recente, Meguri, a fim de contrastar a construção espacial e os movimentos corporais com a construção poética do finado poeta paraense. Enquanto a linguagem poética de Max Martins provoca a coagular as palavras como se fossem corpos, os corpos dos dançarinos do Sankai Juku vivenciam a imobilidade do painel no fundo e do tempo, o lírio do mar.

A nossa reflexão teórica vai na direção do corpo, da materialidade fonética do significante que transmite algo mais do que o significado, último mais fácil de traduzir. A poesia de Max Martins é significante e significado, e expressa isso de maneira ímpar: na recitação dos poemas (e o melhor recitador foi o próprio poeta) o significado desaparece, e no recitar permite-nos sentir a corporalidade da palavra, mastigada, apertada, acariciada com o órgáo próprio da fala: a boca, a língua e os dentes. E como a boca pode acariciar, chupar, mastigar e apertar o corpo todo, dos pés até a cabeça e particularmente os orgãos sexuais, as palavras perdem a forma da escrita e se tornam sons, toques no espaço físico e temporal do mundo, o que significa para Maurice Merleau-Ponty "estar no mundo" (1999).

$\mathrm{O}$ que precisamente foi Safo para os homens e mulheres de Atenas e na ilha de Lesbos,

a língua se parte; debaixo da minha pele

[...]

e o puro orvalho se estende, quando se abrem as rosas, o khairéphylon delicado e o trevo-de-cheiro;

[...]

suaves amigas, vamos

há muito tempo, eu me lancei

[...]

o corpo, sobre um leito macio

reclinar

(Fragmentos do livro Variaçóes sobre a lírica de Safo $)^{18}$

18 "A poesia de Safo exige do tradutor [...] ouvidos atentos aos sentidos misteriosos da língua grega, delicadíssimo sistema fonético, semântico e sintático", constata Joaquim Brasil Fontes (1992, p. 15), mas o que significa "sentidos misteriosos" se o leitor náo sabe mais como a palavra soara e suará? 
foi Max Martins em Belém e na ilha de Mosqueiro/Marahu.

\author{
COM A BOCA \\ Com o imundo \\ (e a catástrofe em silêncio) \\ Aprendeste esta fala \\ esta areia de mim \\ agora alheia \\ resposta que esfria \\ Com a boca \\ Tocaste o imundo \\ Felaste esta fala \\ de esquecimento maduro \\ Aprendeste o coágulo \\ (MARTINS, 2001, p. 90)
}

Na peça recente Meguri. Exuberância marinha, terra tranquila (Figura 10), o grupo Sankai Juku estreiou, em 2015, no Teato de Arte, localizado na província de Kyushu, no Japão, retornando às suas origens. No catálogo impresso em língua portuguesa e distribuído por ocasião do espetáculo em São Paulo, discorre-se que o grupo Sankai Juku "desvia-se de uma investigação antropocêntrica" e, continua o catálogo do espetáculo, "possibilita ao espectador observar, através dos corpos humanos, o modo como se movimentam e se comportam os elementos que constituem o planeta e também, o universo". Trata-se de uma contemplação sobre o lírio do mar fossilizado. São animais parecidos com plantas que vivem no fundo do mar desde a era $\mathrm{Pa}-$ leozoica. Ushio Amagatsu, o fundador e coreógrafo do grupo, ficou fascinado e foi impulsionado para o espetáculo. "Esse lírio do mar se formou na época em que os mares e as terras estavam trocando de lugar. Naquele tempo, ele se movia. Depois, virou pedra, fóssil, ficou imóvel”, diz Amagatsu (BIDERMAN, 2016, p. 8), e nessa relação entre o dinâmico e o estático a peça se apresenta. Os corpos em branco, imitando os movimentos dos líros, representam o espaço (a folha da poesia) branco; os corpos ganham movimentos pequenos, dissincronizados em sua maioria, quase convulsivos por vezes. O espectador contempla sem saber conscientemente que, durante a apresentação, o painel das réplicas de fóssil que criava o cenário por meio das va- 
riaçóes de cores na iluminação havia uma única vez se movimentado quase que imperceptivelmente, imitando o movimento da Terra e da vida, contrastando com o movimento dos corpos, representaçóes que transitam entre o corpo morto para além da morte e da vida.

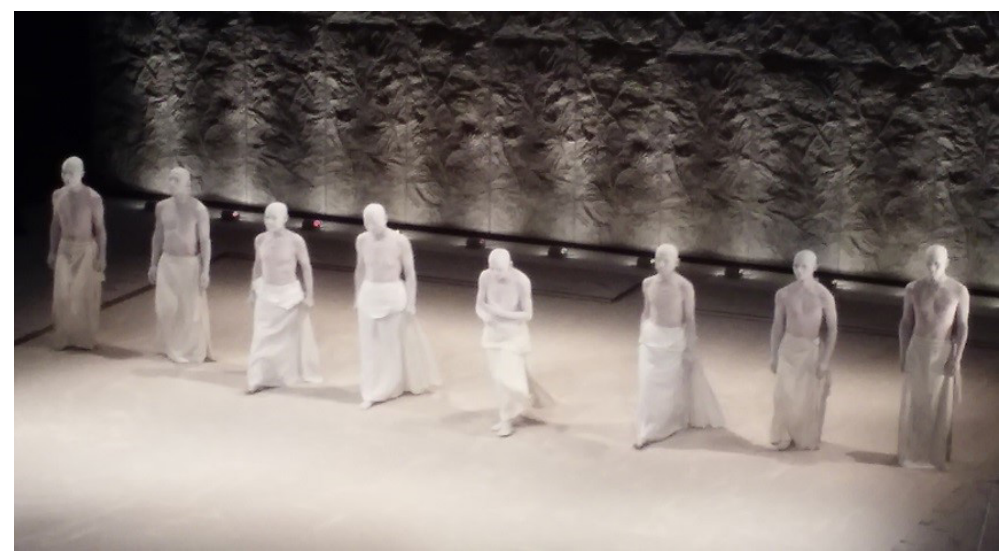

Figura 10: Aplausos finais, 24/07/2016, São Paulo (Fotografia dos autores).

Enquanto a linguagem de Max Martins coalha as palavras como se fossem corpos líquidos, os corpos dos dançarinos vivenciam o passar do aquático ao mineral; seres mortos e vivos, com as bocas escancaradas, sem gritos. Ou gritos silenciosos, que convergem em suas bocas as palavras náo ditas de cada membro do público que assistiu de forma silenciosa ao espetáculo, instigado por meio da sensibilidade, uma experiência profícua. O corpo dos atores desnudos de suas identidades representa o que Slavoj Zizek (1992) professa com o sujeito em si? O silêncio, então, é rompido por aplausos finais. Terminou. E o vazio retoma o palco, que lembra o vazio interno, talvez o ma até que se preencha novamente com a memória das imagens fantasmagóricas que insistem em querer preenchê-lo.

\section{Referências bibliográficas}

BAKHTIN, Mikhail.O problema do conteúdo, do material e da forma na criação literária. In: - Questóes de literatura e de estética: A 
teoria do romance. Trad. Aurora F. Bernadini e outros. São Paulo: Hucitec,(2010 [1924]), p. 13-70.

BARK, Irene. Novalis Philosophie und Poetik des Kristalls im Kontext der zeitgenössischen Naturwissenschaft [A filosofia e poética do cristal de Novalis no contexto das ciências naturalis do seu tempo]. In: CERCIGNANI, Fausto (Org.). Studia Theodisca Novalis. eBook do International Jornal Studia theodisca (Milano/Itália), (2011 [2002]), p. $87-110$.

BENJAMIN, Walter. Sobre a linguagem em geral e a linguagem do homem. In: Escritos sobre Mito e Linguagem. [1916]. São Paulo: Livraria Duas Cidades/Editora 34, 2011. [Org. Jeanne Marie Gagnebin; Trad. Susanne Kampff-Lages/Ernani Chaves. Coleção Espírito Crítico].

. Passagens. [1982]. Belo Horizonte/São Paulo: EDUFMG; Imprensa Oficial do Estado de São Paulo, 2006. [Org. Willi Bolle; trad. Irena Aron].

- Reflexóes: a criança, o brinquedo, a educação. [1984]. Sáo Paulo: Livraria Duas Cidades/Editora 34, 2002. [Tradução, apresentação e notas: Marcus Vinicius Mazzari. Coleção Espírito Crítico. Trata-se de uma reunião de artigos escritos entre 1913 e 1932].

- Obras Escolhidas II (Rua de Mão Única). [1926]. São Paulo: Brasiliense, 1987. [Trad. Rubens Rodrigues Torres Filho/ José Carlos Martins Barbosa].

BIDERMAN, Iara. Grupo japonês investiga os ciclos da terra. Folha de São Paulo, cad. Ilustrada, São Paulo, 23/07/2016, p. 8.

CAMPOS, Haroldo de. O Texto como Descomunicação. In: . $A$ Operação do Texto. São Paulo: Perspectiva, 1976, p. 89-102.

. Haicai: Homenagem à Síntese. [1969]. In: . A Arte no Horizonte do Provável. São Paulo: Perspectiva (Série Debates No. 16), 1977 , p. 55-62.

. Visualidade e Concisão na Poesia Japones. [1969]. In: . A Arte no Horizonte do Provável. São Paulo: Perspectiva (Série Debates No. 16), 1977, p. 63-75.

A palavra vermelha de Hoelderlin. In: A Arte no Horizonte do Provável. São Paulo: Perspectiva (Série Debates No. 16), 1977, p. 93-107.

. (Org.). Ideograma. Lógica, Poesia, Linguagem. [1977]. 3.ed. São Paulo: EDUSP, 1994. 
COLLECTANEVS. Revista Cultural Internacional. ¿Puede la Pornografía ser arte Política? Um artigo com trechos de entrevista com Santiago Sierra, n. 7, agosto/setembro de 2009.

DERRIDA, Jaques. De lagrammatologie. Paris: Les Éditions de Minuit, 1967 (Collection Critique).

. Gramatologia. [1967]. Trad. Miriam Schnauderman e Renato Janini Ribeiro. São Paulo: Perspectiva, 1973 (Série Estudos 16).

EAGLETON, Terry. Teoria da Literatura: uma Introdução. [1983]. $3^{a}$ ed., São Paulo: Martins Fontes, 1997. Trad. Waltensir Dutra.

FONTES, Joaquim Brasil. Variaçôes sobre a lírica de Safo. São Paulo: Estação Liberdade, 1992.

FURRER, Beat. La bianca notte. Disponível em: <https://www.youtube. $\mathrm{com} /$ watch?v=wgFnB0-bgi8>. Acesso 28/07/2016.

GREINER, Christine. Butô: pensamento em evolução. São Paulo: Escrituras, 1998.

HAERDTER, M.; KAWAI, S. (orgs.). Butoh. Die Rebellion des Körpers. Ein Tanzaus Japan. Berlin: Alexander, 1986.

HALL, Stuart. A identidade cultural na pós-modernidade. [1992]. Trad. Tomaz Tadeu da Silva, Guacira Lopes Louro. Rio de Janeiro: DP\&A, 2004.

HAN, Byung-Chul. Sociedade de cansaço. [2010]. Trad. Enio Paulo Giachini. Petrópolis: Vozes, 2015.

HAUBENSACK, Edu. Musik ohne Gewicht. [Música sem peso]. Zürich, Neue Zürcher Zeitung, 10 jan. 2015. Disponível em: <https:// www.nzz.ch/feuilleton/musik/musik-ohne-gewicht-1.18457880>.

ISER, Wolfgang. O Ato da Leitura. Uma Teoria do Efeito Estético. [1976]. v. 2. Trad. Johannes Kretschmer. São Paulo: Editora 34, 1999.

KAMPFF-LAGES, Susana. Walter Benjamin. Tradução \& Melancolia. São Paulo: EDUSP, 2002.

KATO, Shuichi. Tempo e Espaço na Cultura Japonesa. [2007]. Trad. Neide Nagae e Fernando Chamas. São Paulo: Estação Liberdade, 2012.

KIMMEL, Michael I. Masculinity as homophobia: Fear, Shame and Silence in the construction of gender identity. In: BROD, H.; KAUFMAN, M. Theorising Masculinities. London: Sage, 1994, p. 119-143.

KURIHARA, Nanako. Hijikata Tatsumi. The words of Butoh. The Drama Review, v. 44, v. 1 (T165), 2000, p. 10-28. 
MARTINS, Max. Der Ort wohin. Gedichte. [1992]. Trad. Burkhard Sieber. Berlin: Kato Kunst \& Verlag, 2006. . Poemas Reunidos 1952-2001. Belém: EDUFPA, 2001.

MERLEAU-PONTY, Maurice. Fenomenologia da Percepção. [1945]. Trad. Carlos Alberto Ribeiro de Moura. 2a ed., São Paulo: Martins Fontes, 1999.

MINISTÉRIO DA CULTURA. Governo do Estado de São Paulo. Sankai Juku em Meguri. 2016.

NUNES, Robsonde Souza. Haikai e performance: Imagens poéticas. Belo Horizonte: EDUFMG, 2011.

OKANO, Michiko. Ma - A estética do "entre". Revista USP, São Paulo, n. 100, 2014, p. 150-164.

PASZKOWSKA, Alexandra. Butô-Tanz. UshioAmagatsuund die Sankai Juku Gruppe. München: Schirmer/Mosel, 1983.

PERRONE-MOISÉS, Leyla. Outras Margens. "Pensamento alterou rumos da crítica e da teoria". Folha de S.Paulo, São Paulo, Caderno: MAIS!, 3 de dezembro de 1995, p. 6.

PRESSLER, Gunter K. Acima do Abismo a Aura. Para Ter onde Ir. In: CHAVES, Lílian; NASCIMENTO, Mária de Nazaré do (Orgs.). Prata de Casa brilha: Primeiros Estudos sobre a Poesia de Max Martins. Campinas/SP: Pontes, 2018, p. 7-30.

QUEIROZ, José Francisco da Silva. Max Martins: Tradutor do Haikai (manuscrito inédito).

- Por uma História da Recepção da Obra de Max Martins. Petrópolis: Pontes 2017.

SAID, Edward. Orientalismo: o Oriente como invenção do Ocidente. Trad. Tomás Rosa Bueno. São Paulo: Companhia das Letras, 2003.

SCHÄFFAUER, Markus. Script Oralidade in der argentinischen Literatur. Frankfurt a.M.: Vervuet, 1998 (Iberoamericana).

SCHMID, Wolf. Elemente der Narratologie. $3^{\text {a }}$ ed. Berlin/Boston: Walter de Gruyter (Estudium), 2014.

SCHOBER, Anna. Ironie, Montage, Etfremdung. Ästhetische Taktiken und die politische Gestalt der Demokratie. München: Wilhelm Fink, 2009.

SIERRA, Santiago (dir.). Los Penetrados. 2008 Videoart. Produït per Nanouk Films, Colosé Producciones i Common Films. Helga de Alvear Gallery: Madrid. Disponível em: <http://nanouk.tv/archivos/5142?lang=ca>. 
SPIVAK, Gayatri C. Translator's Preface. In: DERRIDA, Jacques. Of Grammatology. Baltimore: John Hopkins University Press, 1997.

STADLER, Ulrich. Überlegungen zur frühromantische Poetik des Kleinen. [Consideraçóes sobre a poética romântica do pequeno]. In: CERCIGNANI, Fausto (Org.). Studia Theodisca Novalis, 2011, p. 67-77.

TAKAKURA, Sandra Mina. Dança do Corpo e da Alma. Estudo Comparativo dos Gênios Criativos de Tatsumi Hijikata e Kazuo Ohno. São Paulo: Faculdade Paulista de Artes/Pós-Graduação em Artes Cênicas, 2006.

ULLRICH, Wolfgang. Siegerkunst. Neuer Adel, teure Lust. Berlin: Wagenbach 2016.

ZIZEK, Slavoj. All's well that ends well?. In: For they do not know what they do: enjoyment as a Political Factor. London: Verso, 2008, p. 179-228.

. His Bold Gaze My Ruin Is Writ Large. In: . Everything You Always Wanted to Know about Lacan (But Were Afraid to Ask Hitchcock). London: Verso, 1992, p. 211-263.

Gunter Karl Pressler é professor de Teoria Literária da Universidade Federal do Pará (UFPA) e atúa no Programa de Pós-graduação em Letras e no Programa de Pós-graduação em Linguagens e Saberes na Amazônia. É Mestre pelo Instituto da História da Literatura e Língua Alemã da Ludwig-Maximilians-Universität München (1985) e Doutor pela Universidade de São Paulo (1995). Realizou estudos de Pós-Doutorado no Interdisciplinary Center for Narratology (ICN) da University of Hamburg, Alemanha (2014/2015) e atua nas linhas de pesquisa Literatura - Interpretação, circulação e recepção; Leitura e Tradução Cultural, e desenvolve pesquisas sobre Walter Benjamin, Dalcídio Jurandir, Literatura da e sobre Amazônia, Teoria da Recepçáo, Ficcionalidade/Factualidade e Narratologia. E-mail: gupre@ufpa.br

Sandra Mina Takakura é graduada em Língua inglesa e Língua Portuguesa pela Universidade Federal do Pará (UFPA) e Mestre em Língua inglesa e literatura correspondente pela Universidade Federal de Santa Catarina (UFSC). Atualmente é doutoranda pela Universidade de São Paulo (USP), sendo uma das teorias de pesquisa de seu interesse a intermidialidade que se demonstram nas produçôes contemporâneas, entrelaçando as várias esferas de conhecimento como as artes, em seu sentido mais restrito, e a literatura. E-mail: sandramita@hotmail.com

Recebido em: 16/01/2018

Aceito em: 15/07/2018 